\title{
Comparative Analysis of Energy Performance for Residential Wall Systems with Conventional and Innovative Insulation Materials: A Case Study
}

\author{
Xinrui Lu, Ali Memari \\ Department of Civil and Environmental Engineering, Pennsylvania State University, University Park, PA, USA \\ Email:amm7@psu.edu
}

How to cite this paper: Lu, X.R. and Memari, A. (2019) Comparative Analysis of Energy Performance for Residential Wall Systems with Conventional and Innovative Insulation Materials: A Case Study. Open Journal of Civil Engineering, 9, 240-254. https://doi.org/10.4236/ojce.2019.93017

Received: July 2, 2019

Accepted: September 13, 2019

Published: September 16, 2019

Copyright () 2019 by author(s) and Scientific Research Publishing Inc. This work is licensed under the Creative Commons Attribution International License (CC BY 4.0).

http://creativecommons.org/licenses/by/4.0/

(c) (i) Open Access

\begin{abstract}
This study was focused on the simulation of energy performance for residential buildings incorporating different types of insulation materials. The energy consumption of residential buildings in the U.S. plays a significant role in the total annual energy consumption, and using insulation materials of higher performances is one of the most effective ways to reduce the building energy consumption. In this study, the building energy simulation was performed in BEopt for a typical residential house in the U.S. with several different types of insulation materials. The results show that adding insulation materials can significantly improve the building energy performance. The polyisocyanurate performed the best among the conventional insulation materials and had an annualized source energy saving of $37 \%$ in Pittsburgh. Vacuum-Insulated Panels had the best performance among all types of materials discussed in this study and showed annualized source energy of $41 \%$ in Pittsburgh. Phase Change Material was found to be the most effective way to particularly reduce the cooling energy use.
\end{abstract}

\section{Keywords}

Insulation Materials, Building Envelope, Energy Performance, BEopt Modeling

\section{Introduction}

The energy consumption of the U.S. residential buildings accounts for $22 \%$ of the total energy use, with about $42 \%$ due to heating and cooling loads. With the increasing demand of energy saving in building sectors in recent years, any 
technique that can demonstrate a reduction in building energy consumption is highly desirable. One of the effective ways to decrease the building energy use is to improve the performance of building envelopes, which account for $36 \%$ of the overall building energy consumption due to heat gain and loss [1].

There are many solution methods applicable to building envelope systems to enhance building energy efficiency. This study is focused on comparison of several types of insulation materials that are suitable for residential wall panels, showing their performance with respect to energy saving. In this paper, firstly, the performances of different wall insulation materials are presented, both conventional and innovative, together with relevant properties that affect the thermal behavior such as the thermal resistance (R-value). Then the literature review section introduces the relevant studies in this field. The paper then discusses the results obtained from BEopt computer simulation, which mainly compares the energy consumption of a single-family residential house with different insulation materials. The insulation materials discussed in this study contain conventional types such as cellulose fiber, mineral wool, expanded polystyrene (EPS), extruded polystyrene (XPS) and polyisocyanurate, as well as innovative types such as Vacuum-Insulated Panels (VIP), aerogel, and phase change materials (PCM). As those conventional types of insulation materials are widely used in the residential housing industry in the U.S., their energy performances compared with those emerging innovative insulation materials are of particular interest. This paper aims to provide an introductory review of insulation materials as well as a quantitative energy analysis, which can help building owners and designers to make better decision especially when energy saving of the building becomes essential.

\section{Literature Review}

\subsection{Conventional Insulation Materials}

There are several types of commonly used insulation materials for walls including cellulose fibers, mineral wool, expanded polystyrene (EPS), extruded polystyrene (XPS) and polyisocyanurate. This section briefly introduces the application of conventional insulation materials and their properties.

\subsubsection{Cellulose Fiber}

Cellulose fiber insulation (CFI) products are made of paper stocks mixed with other chemical components to increase resistance to fire and corrosion and to impart other desired characteristics. The thermal resistance (R-values or RSI) usually varies within an acceptable range from $0.62-0.69 \mathrm{~m}^{2} \mathrm{~K} / \mathrm{W}$ per $25.4 \mathrm{~mm}$ (3.5 - $3.9 \mathrm{ft}^{2} .^{\circ} \mathrm{F} \cdot \mathrm{h} / \mathrm{BTU}$ per inch), and the density is about $24-56 \mathrm{~kg} / \mathrm{m}^{3}$ for sprayed type [2].

Ojanen and Laaksonen [3] have shown that one of the important characteristics of cellulose fiber is its hygroscopicity property, which means that rather than being considered as a complete vapor barrier, it will let moisture (vapor) pass 
through in a buffering way. Accordingly, this effect can regulate (smooth down) the humidity variation so the structure can maintain a stable relative humidity level and therefore maintain comfortable indoor conditions. Ojanen and Laaksonen [3] have used computer modeling to simulate the influence of the hygrothermal performance of cellulose fiber on the indoor air humidity and also the heat flow through the inside surface of the structure. It turns out that hygroscopic structures undergo an apparently lower increase in relative humidity at night time compared with non-hygroscopic structure. The results show that the occurrence of extreme humidity level in hygroscopic structure is much less than non-hygroscopic structure, and therefore the indoor condition will be more comfortable.

\subsubsection{Mineral Wool Insulation}

Mineral wool is made of melted raw materials such as stone, dirt, slag and some chemicals, which are then turned into thin fibers that will be adhered together after being coated with binders and slightly compacted to form insulation batt. Mineral wool has high fire resistance without any use of other "flame retarders", and also a relatively high thermal resistance, which makes it a good insulation material. The acceptable range of R-value for mineral wool is generally considered similar to cellulose fiber insulation. Mineral wool, on the other hand, does have some drawbacks. One is that mineral wool dust will cause health problems when they break off and get airborne and pollute indoor air. LEED (Leadership in Energy and Environmental Design) has categorized mineral wool as "hazardous materials" and therefore cannot be used to pursue the Materials and Resources Credit: Construction and Demolition Waste Management.

Comparisons between mineral wool and other insulation materials have been made by researchers concerning the environmental impact and health problem. According to Papadopoulos [4], mineral wool is a relatively good insulation material when we are concerned with the embodied energy, the use of raw resources and also the waste disposal. It's usually used for wall, roof and ceiling cavities to fit between studs, joists or rafters [4].

\subsubsection{Rigid Board Insulation}

The following three commonly used rigid board insulation types are chosen for discussion in this study: expanded polystyrene (EPS), extruded polystyrene (XPS) and polyisocyanurate, which is usually referred to polyiso. A brief introduction of each of these rigid board insulations follows.

\section{Expanded polystyrene (EPS):}

Usually used in walls, roofs and floors, EPS with R-value in the range of 0.63 $0.70 \mathrm{~m}^{2} \mathrm{~K} / \mathrm{W}$ per $25.4 \mathrm{~mm}\left(3.6-4.0 \mathrm{ft}^{2} .^{\circ} \mathrm{F} \cdot \mathrm{h} / \mathrm{BTU}\right.$ per inch) has the lowest thermal resistance among these three insulation materials, but is the most affordable of the three, meaning that it has the highest "thermal resistance (R-value) per dollar". However, it can be more easily damaged than the other two. It is available in faced or unfaced forms, with the faced EPS form also functioning as a va- 
por retarder. While both EPS and XPS look similar, EPS is actually lighter.

\section{Extruded Polystyrene (XPS):}

Extruded polystyrene comes in the form of blue or pink board. The cost and thermal resistance are both in the middle range of these three types of rigid-foam insulations. Because it is stronger and denser than EPS, XPS boards are typically used in walls and below-grade slabs and foundation walls. XPS is considered semipermeable. The generally accepted R-value for XPS is around 0.79 $0.88 \mathrm{~m}^{2} \mathrm{~K} / \mathrm{W}$ per $25.4 \mathrm{~mm}$ (4.5 - $5.0 \mathrm{ft}^{2} .^{\circ} \mathrm{F} \cdot \mathrm{h} / \mathrm{BTU}$ per inch).

\section{Polyisocyanurate:}

Polyisocyanurate, often referred to as polyiso, is the most expensive one of these three rigid-board insulation types. It also has the highest thermal resistance, often considered as high as $1.23-1.41 \mathrm{~m}^{2} \mathrm{~K} / \mathrm{W}$ per $25.4 \mathrm{~mm}(7.0-8.0$ $\mathrm{ft}^{2} .^{\circ} \mathrm{F} \cdot \mathrm{h} / \mathrm{BTU}$ per inch). There is often a reflective foil facing on both faces of the board, giving it significant resistance to radiant heat transfer. A reported issue with polyisocyanurate is that with the gas trapped in the cells escaping, the R-value may slightly decrease over time.

A case study was carried out by Cabeza et al. [5] to test the performance of different thermal insulation materials. In that study, the authors determined the energy consumption for cooling in summer for cubicles insulated by polyurethane, EPS and mineral wool, and compared these cases with the reference cubicle without any insulations [5]. The results show that all these three insulation types can lead to significant energy saving, with the energy-saving of polyurethane for the measured time period being smaller than the other two. For the period of measurement, the overall energy saving of polyurethane insulation was $55 \%$ compared with the reference cubicle without any insulation [5].

\subsection{New Insulation Technologies}

\subsubsection{Vacuum-Insulated Panels}

While increasing demand for building energy saving can be met even with the use of traditional insulation materials, there is room for more efficiency since such materials generally require thicker walls to achieve a desired thermal resistance, sometimes as thick as $50 \mathrm{~cm}$, which affects the overall floor area available for architects to work with. One of the most effective solutions is to insulate the building envelope using Vacuum-Insulated Panels (VIP), which offers very effective insulation within limited thickness and can have a thermal conductivity typically ranging from $0.004 \mathrm{~W} /(\mathrm{mK})$ to $0.008 \mathrm{~W} /(\mathrm{mK})$. That means with the same insulation thickness as a typical rigid insulation, VIP is able to provide thermal performance 5 - 10 times better than the traditional materials [6]. A VIP usually consists of a porous core enveloped by multiple layers. The use of porous material with small pore sizes enables the inside air to evacuate while also supporting the outside envelope layers. Since the core provides both thermal and mechanical properties to the insulation, there are some requirements when people choose the core materials. The core diameter needs to be small and the 
core structure needs to be fully open to allow air to evacuate. Because the core also undergoes compression, it needs to have sufficient strength. Another important point is to have the core material be impermeable to infrared radiation to reduce the radiative heat transfer and thus provide the expected thermal performance. Different core materials are available; for example, fumed silica, polyurethane foam, and glass fibers have already been used for this purpose [6].

It is worth mentioning that Mujeebu et al. [7] have studied the performance of nanogel glazing and nano-VIPs by using ECOTECT simulation tool and have concluded that VIPs in walls and roofs are not cost-effective compared with traditional rigid-board insulation, but that nanogel glazing for use in windows may have merit.

\subsubsection{Aerogel}

Aerogel is a new material that has a wide range of application. It is the solid component of a silicone gel isolated from its liquid component. In other words, aerogel is what will be left over if the liquid part of a gel is removed while the volume remains not significantly changed [8]. It has nano-porous structure and the thermal conductivity can be as low as $0.015 \mathrm{~W} / \mathrm{mK}$, which makes it possible for good thermal insulation of building envelope system. Currently, there are very few types of commercial aerogel products in the U.S.

Aerogel can be blended with other materials to make an opaque insulation board, and it is neither flammable nor hydrophilic. An example of aerogel insulation board is one called SLENTITE developed by the BASF Chemical Company in Germany as a high-performance aerogel thermal insulation board [5]. The case study made by Filate [8] is an old building in Germany constructed in 1906-1907. It has no insulation on the exterior walls. One of the retrofit methods determined is to remove the existing external clinker finishing and instead add a $50 \mathrm{~mm}$ SLENTITE aerogel insulation board, as mentioned above, is added to the wall with thermal conductivity of $0.016 \mathrm{~W} / \mathrm{mK}$. The result shows that the energy loss through external walls (in MWh) decreases from 36 to $11 \mathrm{MWh}$, which is equivalent to a $71 \%$ reduction in heat loss. Filate also shows a comparison of the wall insulation thicknesses needed to achieve a wall U-value of $0.26 \mathrm{~W} / \mathrm{m}^{2} \mathrm{~K}$. Compared with the $115 \mathrm{~mm}$ thickness needed for Mineral Wool insulation, and the $87 \mathrm{~mm}$ thickness needed for Polyurethane insulation board, SLENTITE shows a better performance with a thickness of $50 \mathrm{~mm}$ [8].

\subsubsection{Phase Change Materials}

Phase change material (PCM) is one of the new smart materials that can be used in building envelope systems. Unlike most insulation materials whose capacities depend on the mass of the body of material itself and the specific heat capacity to withstand the external heat without warming up the inside rapidly, PCM acts in the way that it can absorb the external heat in the form of latent heat, which means it undergoes a phase transition, for example from solid to liquid [9]. The PCM concept can be considered in the category of "thermal inertia", rather than 
thermal insulation. The difference is that thermal insulation insulates the building in the way that it slows down the temperature change without any heat storage, whereas PCM's performance consists of absorbing the thermal energy and releasing it at a later time, which could be used to warm up the building. Because PCM helps increase the thermal mass, the temperature oscillation will be decreased and also the response to outside thermal stimuli will be slow.

During daytime, when the temperature exceeds a critical level, it activates the PCM and starts the phase change. The exterior heat is then subtracted from the environment and used for PCM to experience phase transition (i.e., solid to liquid). Then during night time when temperature drops below the set point, the reverse phase transition (liquid to solid) occurs and thus releases heat to the environment, which can be used to warm up the building during the night. It should be noted that PCMs typically need the temperature to exceed a certain critical level in order to be activated; that means in winter at some regions the PCM may never work due to the low outside temperature.

\section{Energy Simulation}

\subsection{General Information}

This section compares different insulation technologies discussed in the previous section based on their energy performance. For this purpose, a comparison baseline, that is, a "reference house" preferably without any type of wall insulation is needed to explore and compare the effectiveness of the conventional and innovative thermal insulation technologies chosen for the study.

To better represent the most common case of buildings, especially for those in cold regions in the U.S., data obtained from U.S. Department of Commerce website for single-family houses are used to build the model in BEopt (https://www.census.gov/econ/construction.html, accessed on 9/3/2018). The most common case of floor area, number of stories, bedrooms, bathrooms and foundation should be selected. Table 1 summarizes the data for modeling, which is chosen from year 2010 to represent the single-family houses.

\subsection{Material Properties}

Since the focus of this study aims to explore the energy performance of different types of insulation materials, therefore the only variables in the simulation

Table 1. Summary of geometric inputs.

\begin{tabular}{cc}
\hline Geometric Properties & Values \\
\hline Square feet of floor area & $242 \mathrm{~m}^{2}\left(2610 \mathrm{ft}^{2}\right)$ \\
Number of bathrooms & 2.5 \\
Number of bedrooms & 3 \\
Number of stories & 2 \\
Type of foundation & Full or partial basement \\
\hline
\end{tabular}


Table 2. Material properties.

\begin{tabular}{cccc}
\hline Materials & Conductivity $(\mathrm{W} / \mathrm{mK})$ & Density $\left(\mathrm{kg} / \mathrm{m}^{3}\right)$ & Specific Heat $(\mathrm{J} / \mathrm{kg}-\mathrm{K})$ \\
\hline Cellulose Fiber & 0.040 & 40 & 2020 \\
Mineral Wool & 0.040 & 48 & 840 \\
EPS & 0.036 & 20 & 1500 \\
XPS & 0.034 & 30 & 1500 \\
Polyisocyanurate & 0.024 & 35 & 1500 \\
Aerogel & 0.014 & 150 & 1000 \\
VIP & 0.0037 & 200 & 800 \\
PCM (Paraffin) & 0.25 & 810 & 2200 \\
\hline
\end{tabular}

model should be the types of insulation materials. All other model details are kept the same. The properties of insulation materials used for simulation are listed in Table 2. In this study, the PCM is selected as paraffin, which is a typical phase change material used in drywall. Aside from the information listed below, the latent heat for PCM (paraffin) is $200 \mathrm{~kJ} / \mathrm{kg}$ and the melting temperature is $25^{\circ} \mathrm{C}$. These two properties are also necessary for modeling PCM.

\subsection{Wall Section}

To represent the most typical case of residential wall system in the U.S., the mostly used $50.8 \mathrm{~mm}{ }^{*} 101.6 \mathrm{~mm}\left(2\right.$.in ${ }^{*} 4$.in) wood-stud wall is selected for simulation. The OSB sheathing layer and vinyl siding layer are kept the same for each case to control variable. Different types of insulation materials are selected for the $101.6 \mathrm{~mm}$ (4.in) insulation layer with properties described in Section 3.2. A section of the modeled wall is shown in Figure 1. It should be noted that PCM is usually not used as a separate "insulation layer" like EPS or cellulose fiber to fill in the space between studs, rather it is used in the drywall together with other insulation materials. Therefore, PCM is defined as the "exterior wall thermal mass" in BEopt modeling. The "reference house" serving as the baseline of the comparison does not have the insulation layer, therefore any improvement in energy performance due to the addition of insulation can be directly quantified.

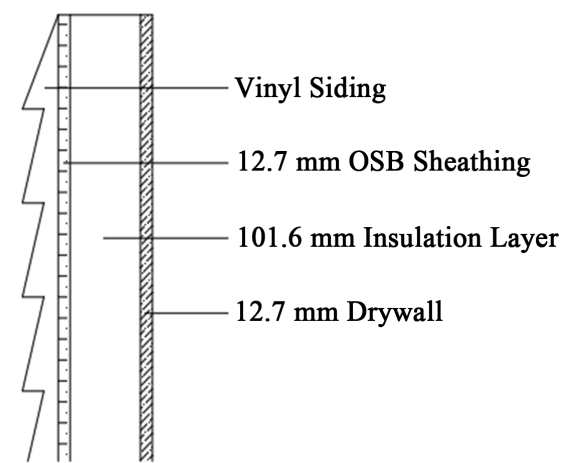

Figure 1. Wall section. 
Table 3. Simulated cases.

\begin{tabular}{cc}
\hline Case Number & Insulation Materials Used in Wall \\
Baseline & No Insulation \\
CF & Cellulose Fiber \\
MW & Mineral Wool \\
EPS & Expanded Polystyrene \\
XPS & Extruded Polystyrene \\
Poly & Polyisocyanurate \\
VIP & Vacuum-Insulated Panels \\
Aero & Aerogel \\
CF-P & Cellulose Fiber with PCM in Drywall \\
MW-P & Mineral Wool with PCM in Drywall \\
EPS-P & EPS with PCM in Drywall \\
XPS-P & XPS with PCM in Drywall \\
Poly-P & Polyisocyanurate with PCM in Drywall \\
VIP-P & Aerogel with PCM in Drywall \\
Aero-P &
\end{tabular}

Table 4. BEopt inputs.

\begin{tabular}{cc}
\hline BEopt Options & Properties \\
\hline Cooling Set Point & $24.4^{\circ} \mathrm{C}\left(76^{\circ} \mathrm{F}\right)$ \\
Heating Set Point & $21.7^{\circ} \mathrm{C}\left(71^{\circ} \mathrm{F}\right)$ \\
Central Air Conditioner & SEER 13 \\
Furnace & Gas, $78 \%$ AFUE \\
Air Leakage & 7 ACH50 \\
Mechanical Ventilation & Exhaust, 2010 ASHRAE 62.2 \\
\hline
\end{tabular}

The simulated cases are named corresponding to the different insulation materials used in the wall models, as listed in Table 3.

\subsection{Other BEopt Model Parameters}

Table 4 shows other parameters defined in BEopt. These parameters are kept the same for all cases to control variables. For each case listed in Table 3, the simulation is performed at three different locations: Pittsburgh, Atlanta and Los Angeles for comparison purpose.

\section{Results and Discussions}

The detailed simulation outputs are summarized in Tables 5-7. 
Firstly it can be observed that adding insulation materials can lead to significant reduction in annualized source energy use. Among the conventional insulation materials, the rigid-board insulation types turn out to perform better than cellulose fiber and mineral wool at all locations. The polyisocyanurate insulation is the best-performing one among the conventional insulation materials. The innovative insulation materials, aerogel and VIP, show apparent better performances than the conventional insulation materials as expected. To better visualize the simulation results, the annualized source energy consumptions at the three locations are summarized as percentage saving and plotted in Figures 2-4.

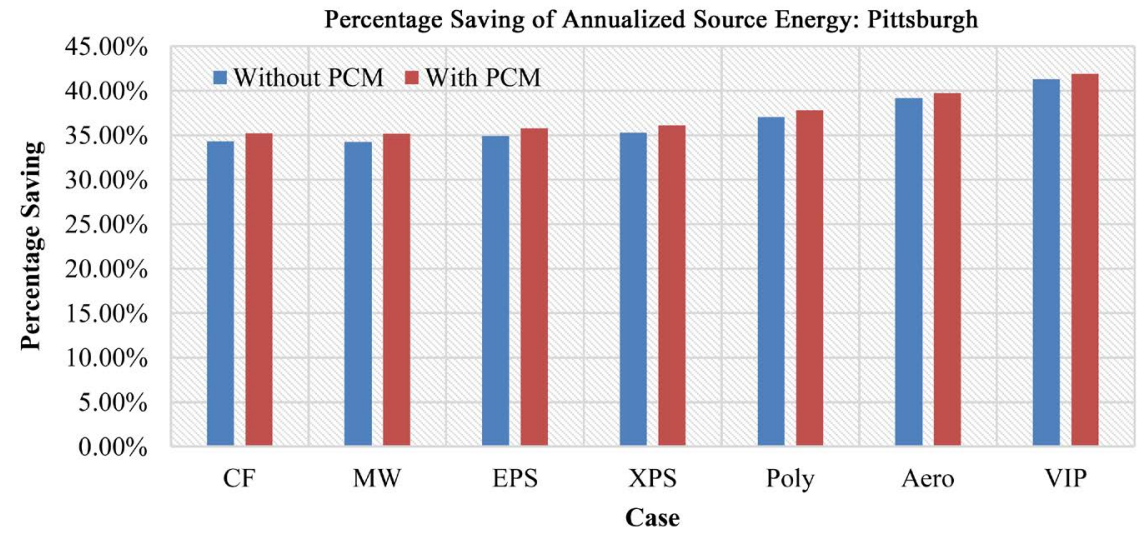

Figure 2. Percentage energy saving of annualized source energy: Pittsburgh.

Table 5. Energy consumption, Pittsburgh.

\begin{tabular}{cccc}
\hline Case & $\begin{array}{c}\text { Annualized Source } \\
\text { Energy }(\mathrm{kWh})\end{array}$ & $\begin{array}{c}\text { Heating Source } \\
\text { Energy Use }(\mathrm{kWh})\end{array}$ & $\begin{array}{c}\text { Cooling Source } \\
\text { Energy Use }(\mathrm{kWh})\end{array}$ \\
\hline Baseline & 95,510 & 55,810 & 2248 \\
CF & 62,750 & 25,830 & 1958 \\
MW & 62,800 & 25,870 & 1975 \\
EPS & 62,190 & 25,290 & 1981 \\
XPS & 61,840 & 24,980 & 1975 \\
Poly & 60,140 & 23,390 & 1981 \\
Aero & 58,120 & 21,550 & 1958 \\
VIP & 56,060 & 19,580 & 2013 \\
CF-P & 61,900 & 25,470 & 1609 \\
MW-P & 61,920 & 25,490 & 1609 \\
EPS-P & 61,340 & 24,930 & 1621 \\
XPS-P & 61,020 & 24,630 & 1627 \\
Poly-P & 59,410 & 23,080 & 1665 \\
Aero-P & 57,560 & 21,320 & 1709 \\
VIP-P & 55,510 & 19,350 & 1767 \\
\hline
\end{tabular}

*The annualized source energy and heating source energy used are rounded to the nearest ten. 


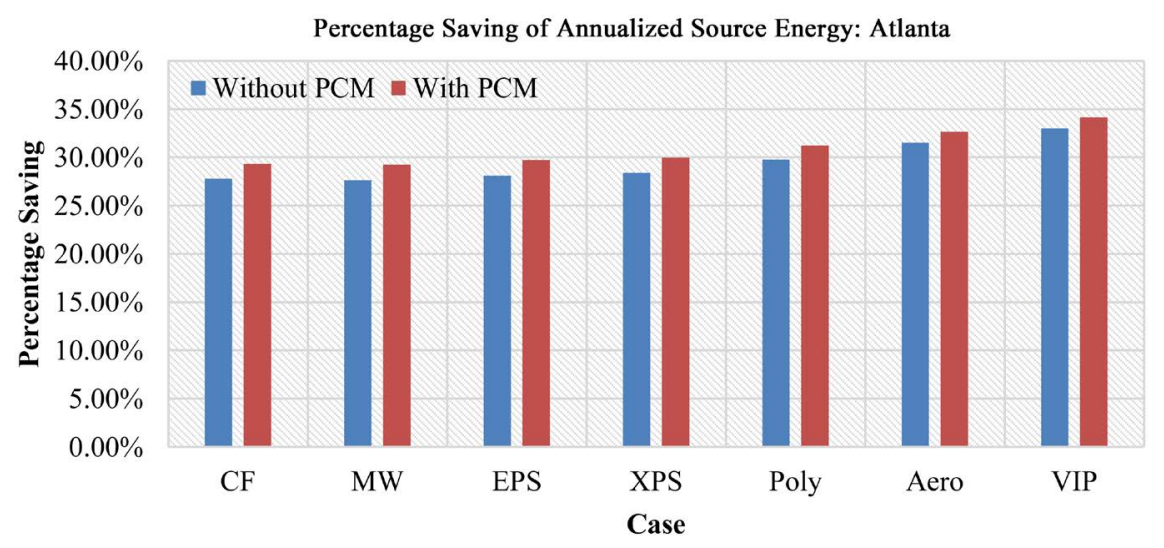

Figure 3. Percentage energy saving of annualized source energy: Atlanta.

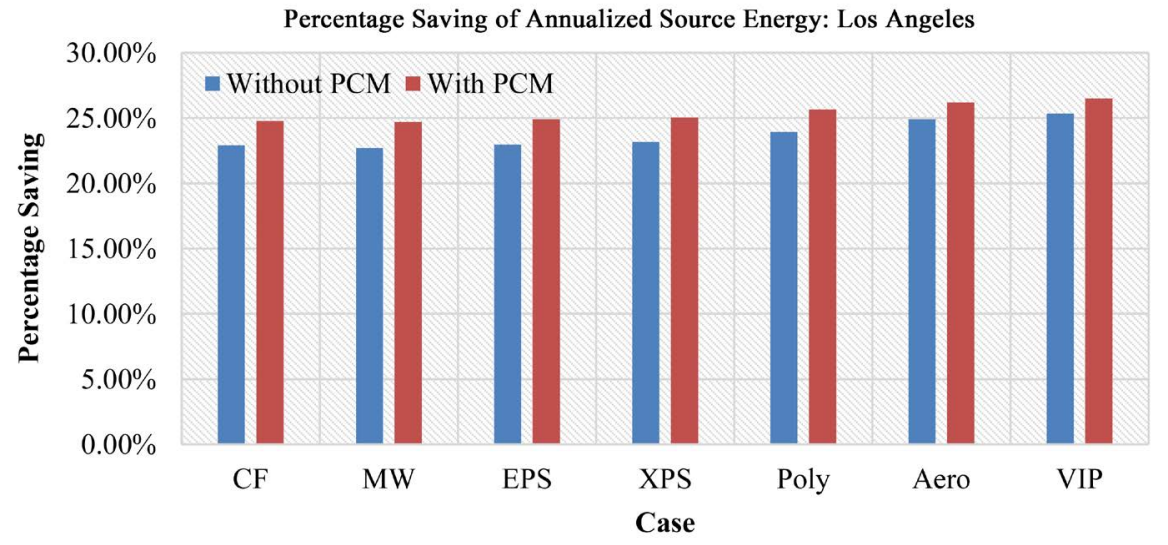

Figure 4. Percentage energy saving of annualized source energy: Los Angeles.

Table 6. Energy consumption, Atlanta.

\begin{tabular}{cccc}
\hline Case & $\begin{array}{c}\text { Annualized Source } \\
\text { Energy (kWh) }\end{array}$ & $\begin{array}{c}\text { Heating Source } \\
\text { Energy Use }(\mathrm{kWh})\end{array}$ & $\begin{array}{c}\text { Cooling Source } \\
\text { Energy Use }(\mathrm{kWh})\end{array}$ \\
\hline Baseline & 68,520 & 26,790 & 6360 \\
CF & 49,500 & 10,530 & 5407 \\
MW & 49,590 & 10,580 & 5436 \\
EPS & 49,270 & 10,280 & 5431 \\
XPS & 49,060 & 10,110 & 5416 \\
Poly & 48,120 & 9260 & 5387 \\
Aero & 46,920 & 8230 & 5307 \\
VIP & 45,920 & 7280 & 5343 \\
CF-P & 48,440 & 10,060 & 4950 \\
MW-P & 48,470 & 10,080 & 4953 \\
EPS-P & 48,150 & 9790 & 4956 \\
XPS-P & 47,980 & 9630 & 4956 \\
Poly-P & 47,130 & 8820 & 4968 \\
Aero-P & 46,160 & 7900 & 4988 \\
VIP-P & 45,130 & 6900 & 5023 \\
\hline
\end{tabular}

${ }^{*}$ The annualized source energy and heating source energy used are rounded to the nearest ten. 
Table 7. Energy consumption, Los Angeles.

\begin{tabular}{cccc}
\hline Case & $\begin{array}{c}\text { Annualized Source } \\
\text { Energy (kWh) }\end{array}$ & $\begin{array}{c}\text { Heating Source } \\
\text { Energy Use }(\mathrm{kWh})\end{array}$ & $\begin{array}{c}\text { Cooling Source } \\
\text { Energy Use }(\mathrm{kWh})\end{array}$ \\
\hline Baseline & 45,690 & 12,620 & 586 \\
CF & 35,230 & 2365 & 1032 \\
MW & 35,310 & 2421 & 1043 \\
EPS & 35,200 & 2274 & 1073 \\
XPS & 35,110 & 2175 & 1084 \\
Poly & 34,760 & 1753 & 1163 \\
Aero & 34,320 & 1246 & 1240 \\
VIP & 34,110 & 888 & 1395 \\
CF-P & 34,380 & 1937 & 747 \\
MW-P & 34,410 & 1964 & 747 \\
EPS-P & 34,320 & 1823 & 782 \\
XPS-P & 34,260 & 1738 & 803 \\
Poly-P & 33,970 & 1351 & 914 \\
Aero-P & 33,730 & 947 & 1055 \\
VIP-P & 33,590 & 595 & 1240 \\
\hline
\end{tabular}

*The annualized source energy is rounded to the nearest ten.

It can be observed from Figures 2-4 that compared to the reference house with no insulation, all types of insulation materials show apparent improvements in the energy performance for the modeled residential house. In Pittsburgh, using cellulose fiber alone leads to an annualized source energy saving of $34 \%$, while using aerogel and VIP both lead to an energy saving of around $40 \%$. Similar trends can be observed for both Atlanta and Los Angeles.

It may be noticed that the results also illustrate decreasing energy saving percentage with the location of building changing from cold climate region to warm climate region. For example, XPS working alone has an annualized source energy reduction of $35 \%$ at Pittsburgh, and such percentage decreases to $28 \%$ at Atlanta and 23\% at Los Angeles. However, this does not mean the materials are "less effective" in warmer regions. The reason is that with the climate becoming warmer, the total amount of energy consumption used for heating also decreases, therefore leading to a lower percentage. Besides, for each type of material, using PCM together with the insulation material itself show a slightly better performance as can be observed from the figures shown above.

To better illustrate the effectiveness of these insulation materials on the heating energy reduction, relevant data extracted from Tables $5-7$ is summarized and plotted in Figures 5-7 as percentage saving.

It can be observed from Figure 5 that insulation materials have a significant contribution to the reduction of heating energy. All types of insulation materials, 


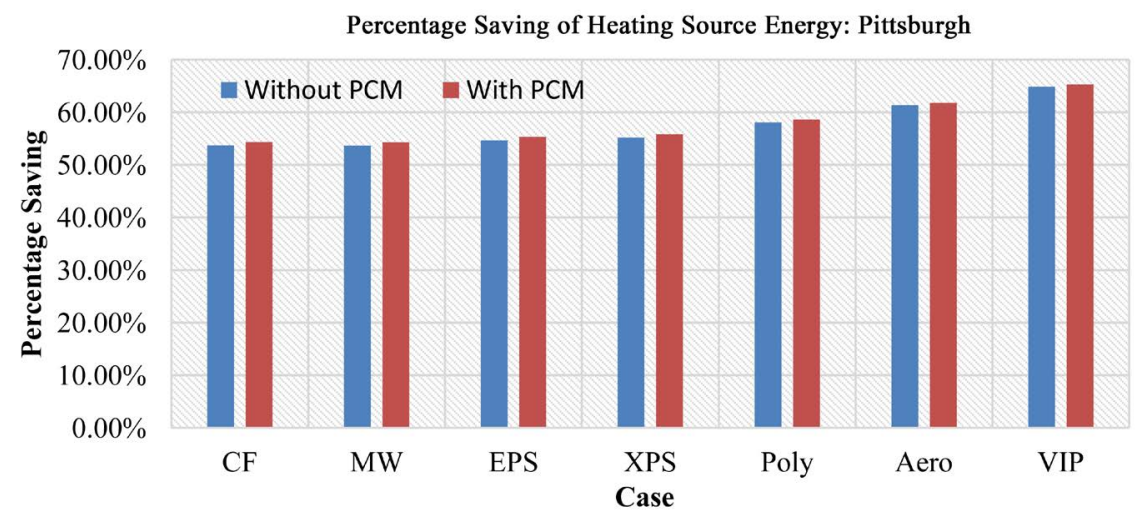

Figure 5. Percentage saving of heating source energy: Pittsburgh.

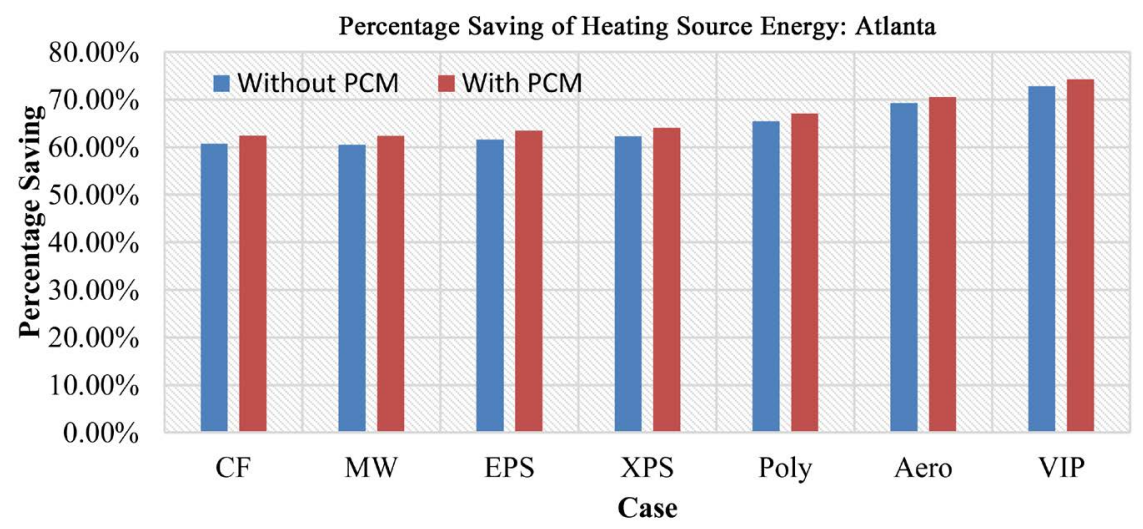

Figure 6. Percentage saving of heating source energy: Atlanta.

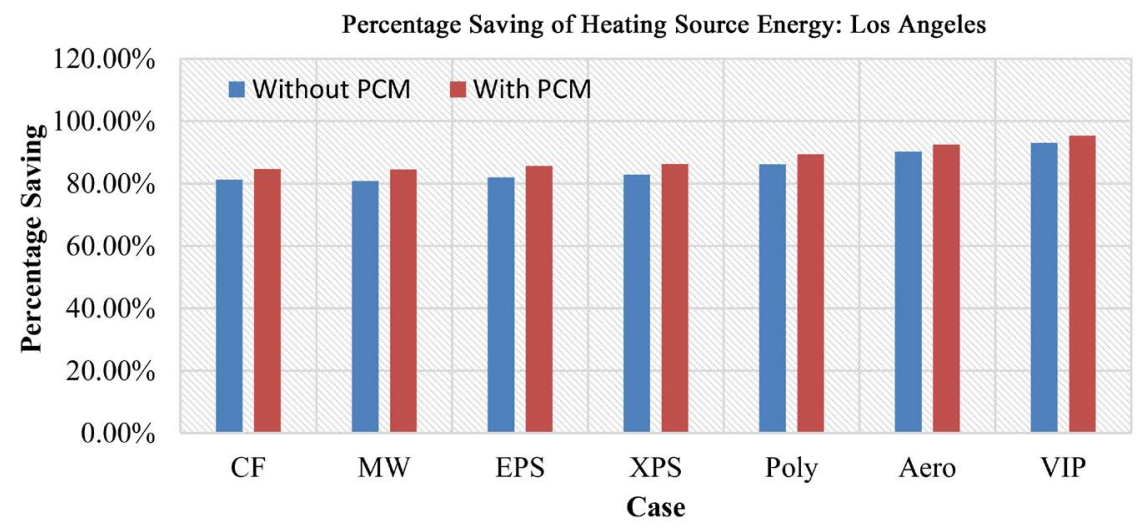

Figure 7. Percentage saving of heating source energy: Los Angeles.

compared to the baseline show improved performance regarding heating energy use with percentage savings above 50\%, while aerogel and VIP have the percentage saving of heating energy over $60 \%$. Adding PCM working with other insulation materials shows slightly better performances. Similar trends can also be observed in Figure 6 and Figure 7. Therefore it can be concluded that among all types of insulation materials discussed in this study, VIP has the best energy performance regarding both annualized source energy saving and heating energy 
saving. Among the conventional insulation materials, the polyisocyanurate turns out to be the best choice.

Again, similar to that has been mentioned in the previous discussion, higher percentage saving shown in Los Angeles does not mean the insulation materials work "more effectively". Because the discussion here is focused on heating energy use, and in Los Angeles the total amount of heating energy consumption is typically lower than in Pittsburgh, therefore it leads to a higher percentage saving.

It should be noted that from Table 5 an interesting phenomenon can be observed. Even though adding insulation does show significant contribution to annualized source energy saving and heating energy saving, and the performance improves with the increase of material thermal resistance as listed in $\mathrm{Ta}$ ble 2, the cooling energy shows different tendency. With the increase of thermal resistance of insulation materials, such as EPS, XPS and polyisocyanurate, all having higher thermal resistances than cellulose fiber and mineral wool, the cooling energy is not necessarily reduced. The polyisocyanurate insulation, even though with a much higher thermal resistance than cellulose fiber and mineral wool, actually turns out to have higher cooling energy consumption. The Vacuum-Insulated Panels has the highest thermal resistance among all types of insulation materials discussed in this study, however, it also shows the most cooling energy consumption in Table 5.

Such phenomenon can also be observed in Table 6 and even more dominant in Table 7, where adding insulation materials turns out to have more cooling energy consumption than the reference house with no insulation. This counterintuitive phenomenon is of interest as it seems to break the general "the more the better rule" rule for insulation materials in building design. Masoso and Grobler [10] first discussed this phenomenon and defined it as "anti-insulation" effect. They stated that this effect is related to the cooling set point and the insulation level. When the cooling set point increases, there is an inflection point in the cooling energy-thermal resistance curve, showing that the cooling energy consumption will start to increase with more insulation. Masoso and Grobler [10] defined the inflection point as "thermal inflection". Idris and Mae [11] also explored this "anti-insulation" effect in another study following the concept of "thermal inflection" proposed by Masoso and Grobler. Idris and Mae explained this effect in the way that at some times, the internal heat from solar heat gain, occupant activities, and other sources and the heat stored in the envelope system are desired to dissipate to the outside environment for cooling purpose, and at that time the existence of high-level insulation actually becomes a barrier. Therefore, for design purposes especially when reduction of cooling energy is of concern, this "anti-insulation" effect should be carefully considered and a whole-building energy simulation is recommended for cases where reaching the expected level of energy-saving is an expectation. 
However, even though increasing the thermal resistance of the wall may not be a good strategy to reduce cooling energy use, using PCM turns out to be effective. PCM working together with cellulose fiber reduces the cooling energy use from $1958 \mathrm{kWh}$ to $1609 \mathrm{kWh}$ in Pittsburgh, and such apparent reduction can also be observed in Atlanta and Los Angeles. Therefore, it can be concluded that using PCM is an effective way to reduce cooling energy use.

\section{Conclusion}

In this study, the energy performances of a residential building incorporating several types of insulation materials are studied by modeling a residential house at three different locations: Pittsburgh, Atlanta and Los Angeles. A side-by-side comparative study was performed for different types of building insulation materials, which provides better understanding and design alternatives for engineers and researchers in this field. The results show that insulation materials have a significant influence on the building energy performance. Compared to the baseline with no insulation, polyisocyanurate has the best performance among the conventional insulation materials, showing an annualized source energy saving of $37 \%$ in Pittsburgh, 30\% in Atlanta and 24\% in Los Angeles. Among all types of insulation materials discussed in this research, VIP is the best performing one regarding both the annualized source energy saving and heating energy use. Using VIP leads to a reduction in annualize source energy saving of 41\% in Pittsburgh, 33\% in Atlanta and 25\% in Los Angeles. However, when the cooling energy is of particular concern, increasing the insulation level (using insulation materials with higher thermal resistance) does not necessarily lead to reduced cooling energy use. The "anti-insulation" effect needs to be taken into consideration and therefore, a whole-building energy simulation is recommended in practical design. The use of PCM, even though just showing slightly better performance working with other insulation materials regarding the annualized source energy and heating energy use, has a significant contribution to the reduction of cooling energy use. This study has provided a quantitative comparison of different building insulation materials for a typical residential building, which can aid engineers to choose insulation types in practical design. Future studies may focus on the influence of insulation materials in different building envelope systems, such as light-frame wall, masonry wall, concrete block wall, etc. Moreover, it is also desired that follow-up studies validate the simulation results by performing in-situ energy consumption measurement for real buildings.

\section{Acknowledgements}

This research was supported by the Pennsylvania Housing Research Center (PHRC). This support is gratefully acknowledged. The opinions expressed in the report are those of the authors only and do not necessarily reflect those of PHRC. 


\section{Conflicts of Interest}

The authors declare no conflicts of interest regarding the publication of this paper.

\section{References}

[1] Cooperman, A., Dieckmann, J. and Brodrick, J. (2011) Home Envelope Retrofits. ASHRAE Journal, 53, 82-85.

[2] Cellulose Insulation Manufacturers Association of Canada (2009) General Installation Guidelines for Cellulose Fiber Insulation (CFI). 2nd Edition.

[3] Ojanen, T. and Laaksonen, J. (2016) Hygrothermal Performance Benefits of the Cellulose Fibre Thermal Insulation Structures. 41 st IAHS World Congress: Sustainability and Innovation for the Future, Coimbra, 13-16 September 2016, 10.

[4] Papadopoulos, A.M. (2005) State of the Art in Thermal Insulation Materials and Aims for Future Developments. Energy and Buildings, 37, 77-86.

https://doi.org/10.1016/j.enbuild.2004.05.006

[5] Cabeza, L.F., et al. (2010) Experimental Study on the Performance of Insulation Materials in Mediterranean Construction. Energy and Buildings, 42, 630-636. https://doi.org/10.1016/j.enbuild.2009.10.033

[6] Kalnæs, S.E. and Jelle, B.P. (2014) Vacuum Insulation Panel Products: A State-of-the-Art Review and Future Research Pathways. Applied Energy, 116, 355-375. https://doi.org/10.1016/j.apenergy.2013.11.032

[7] Mujeebu, M.A. and Noman Ashraf, A.A. (2016) Energy Performance and Economic Viability of Nano Aerogel Glazing and Nano Vacuum Insulation Panel in Multi-Story Office Building. Energy, 113, 949-956. https://doi.org/10.1016/j.energy.2016.07.136

[8] Filate, S.S. (2014) Investigation of an Energy Refurbishment Concept for Office Building Using Nanogel Aerogel Insulation Plaster and Replaced Windows by Building Simulation.

[9] Casini, M. (2014) Smart Materials and Nanotechnology for Energy Retrofit of Historic Buildings. International Conference on Advances in Civil, Structural and Construction Engineering, Rome, 7-8 June 2014, 28-37.

[10] Masoso, O.T. and Grobler, L.J. (2008) A New and Innovative Look at Anti-Insulation Behaviour in Building Energy Consumption. Energy and Buildings, 40, 1889-1894. https://doi.org/10.1016/j.enbuild.2008.04.013

[11] Idris, Y.M. and Mae, M. (2017) Anti-Insulation Mitigation by Altering the Envelope Layers' Configuration. Energy and Buildings, 141, 186-204.

https://doi.org/10.1016/j.enbuild.2017.02.025 